\title{
Evidence for a Proprioception-Based Rapid On-Line Error Correction Mechanism for Hand Orientation during Reaching Movements in Blind Subjects
}

\author{
Nadia Gosselin-Kessiby, ${ }^{1,4}$ John F. Kalaska, ${ }^{1,3,4}$ and Julie Messier ${ }^{2,5}$ \\ ${ }^{1}$ Département de Physiologie, ${ }^{2}$ Département de Kinésiologie, ${ }^{3}$ Groupe de Recherche en Sciences Neurologiques (Canadian Institutes of Health Research), \\ ${ }^{4}$ Groupe de Recherche sur le Système Nerveux Central (Fonds de la Recherche en Santé du Québec), and ${ }^{5}$ Centre de Recherche Institut Universitaire de \\ Gériatrie de Montréal, Université de Montréal, Montréal, Québec, Canada H3C 3J7
}

The contribution of visual experience to the perception and sensorimotor control of spatial orientation of the hand was investigated in blind subjects. In "orientation-matching" tasks, subjects aligned a match handle held in their right hand to a target handle held in their left hand and fixed in different orientations, with both arms outstretched. In "letter-posting" task 1, the same subjects reached out and simultaneously oriented their right hand to insert the match handle into a target slot fixed in the same range of orientations. Orientations were signaled proprioceptively by a reference handle held in the left hand. Final hand orientation errors were smaller when blind subjects simultaneously reached out and rotated their hand to insert the match handle into the target slot in letter-posting task 1 than when they held their arm extended and aligned the handles in the orientation-matching task. In letter-posting task 2, blind subjects first aligned their hand to the orientation of the target and then subsequently reached to the target with the instruction to not change hand orientation during reaching. Despite the instruction, subjects showed a reduction in absolute hand orientation error from the beginning to the end of the reach. In all tasks, performance of blind subjects was very similar to that of blindfolded normally sighted subjects. These findings provide the first evidence of an automatic on-line error-correction mechanism for hand orientation guided only by proprioceptive inputs during reaching in blind subjects, and reveal that the on-line mechanism does not depend on prior visual experience.

\section{Introduction}

Many studies have reported rapid automatic on-line adjustments for hand spatial location and grip aperture during reaching and grasping (Goodale et al., 1986; Pélisson et al., 1986; Prablanc and Martin, 1992; Desmurget et al., 1999; Day and Lyon, 2000; Desmurget and Grafton, 2000; Gréa et al., 2002; Saunders and Knill, 2004, 2005). In contrast, few studies have investigated such mechanisms for spatial hand orientation (Glover and Dixon, 2001a,b,c; Tunik et al., 2005; Fan et al., 2006; Gosselin-Kessiby et al., 2008).

Furthermore, almost all studies of on-line control examined the corrections evoked by visually observed changes in target location, size, or orientation, and often allowed vision of the hand during the correction. The possible contribution of proprioceptive sensory input is usually not considered. Human sensorimo-

Received May 24, 2008; revised 0ct. 12, 2008; accepted Feb. 12, 2009.

This work was supported by Canadian Institutes of Health Research (CIHR) Operating Grant MOP-62983, the CIHR Group Grant in Neurological Sciences, and an infrastructure grant (Groupe de Recherche sur le Système Nerveux Central) from the Fonds de la Recherche en Santé du Québec (FRSQ) (J.K.), a salary award from the FRSQ (J.M.), and a doctoral studentship from the FRSQ (N.G.K.). We thankS. Turgeon-Londeï, R. Ibrahim, A. Albers, A. Béland, G. Lord, M. Israël, P. M. Gendron, and M. Gosselin-Kessiby for technical assistance and data analysis support. G. Richard built the task apparatus. J. Jodoin provided electronics support. C. Valiquette provided software support. We also thank all our subjects for their participation.

Correspondence should be addressed to John F. Kalaska, Département de Physiologie, Groupe de Recherche sur le Système Nerveux Central (Fonds de la Recherche en Santé du Québec), Université de Montréal, C.P. 6128, succursale Centre-ville, Montréal, Québec, Canada H3C 3J7. E-mail: kalaskaj@physio.umontreal.ca.

DOI:10.1523/JNEUROSCI.2374-08.2009

Copyright $\odot 2009$ Society for Neuroscience $\quad$ 0270-6474/09/293485-12\$15.00/0 tor performance often seems introspectively to be dominated by vision, and proprioception appears to play a minor role. However, quantitative studies have shown that both contribute to movement control and that the relative contribution of each is determined by the relative reliability of the information provided by each modality about different aspects of the task (Rossetti et al., 1995; van Beers et al., 1999, 2002; Ernst and Banks, 2002; Sober and Sabes, 2003, 2005; Saunders and Knill 2003, 2004, 2005; Bagesteiro et al., 2006; Sarlegna and Sainburg, 2007).

A limited number of studies have analyzed reaching and grasping movements when visual information was not available (Wing et al., 1986; Jakobson and Goodale, 1991; Darling and Miller, 1993; Hocherman, 1993; Gaunet and Rossetti, 2006; Coluccia et al., 2007; Gaunet et al., 2007; Gosselin-Kessiby et al., 2008). Some studies suggested that visual feedback or visual experience was not essential for the successful execution of reaching or grasping movements (Jeannerod, 1984; Castiello et al., 1993; Sergio and Scott, 1998; Ittyerah et al., 2007).

Recently, we showed that proprioceptive feedback alone about current and desired final hand orientation was sufficient to initiate and guide rapid on-line adjustments of hand orientation during reaching movements toward a target in blindfolded normally sighted subjects (Gosselin-Kessiby et al., 2008). An interesting question is whether prior visual experience is necessary for the development of rapid on-line correction mechanisms, which then generalize to the proprioceptive domain (Fiehler et al., 
2009). Furthermore, to the best of our knowledge, there is no information in the literature about the ability of blind subjects to use proprioception to guide hand orientation and to make rapid on-line corrections of hand orientation during movements. The present study addressed those issues.

The perception and control of hand orientation was compared across congenitally blind, postnatally blind, and blindfolded normally sighted subjects. Postnatally blind subjects permit an assessment of the possible contribution of some prior visual experience compared with congenitally blind subjects, who have never experienced visual feedback and have no memory of motor performance under visual guidance (Imbiriba et al., 2006).

\section{Materials and Methods \\ Subjects}

Twelve blind subjects (seven congenitally blind, five postnatally blind; seven women, five men; mean age $=39$, range $18-62$ years; Table 1 ) participated voluntarily in this study. Their performance was compared with that of 18 agematched blindfolded normally sighted subjects (nine women, nine men; mean age $=44$, range 18-64 years) reported previously (GosselinKessiby et al., 2008). All subjects, except two blind subjects, were right handed (Table 1). Handedness was assessed using the Edinburgh Handedness Inventory (Oldfield, 1971). None of the normally sighted subjects had a history of neurological problems, and they all had normal or corrected-to-normal vision. All subjects signed a consent form. The Université de Montréal Human Research Ethics Committee approved the experimental protocol. Subjects were not informed about the specific purposes of the study.

The possible contribution of any residual vision in our tasks was assessed by testing the ability of all blind subjects to align their right hand with a visual black bar of the same size as the target and match handle presented on a white background, at the same distance as the target panel. The performance of all blind subjects was no better than random. Nevertheless, the blind subjects wore a blindfold during the experiment to ensure conditions similar to those of the blindfolded normally sighted subjects (Gosselin-Kessiby et al., 2008) and to eliminate the effects of any residual luminescence sensitivity in a few of the blind subjects.

The blind subjects were allowed to reach out and manually explore the area corresponding to the spatial location of the target slot, to locate it spatially before the beginning of each letter-posting task. The normally sighted subjects looked at the task panel to determine the spatial location of the target, but did not manually explore the corresponding area.

\section{Experimental setup and task structure}

The experimental setup and tasks used in this study of blind subjects are identical to the proprioceptive sensory condition described previously for a study of normally sighted subjects (Gosselin-Kessiby et al., 2008). Figure 1 shows the experimental setup. Subjects sat in front of a vertical task panel, on which a target was mounted. The target was either a rect-

B

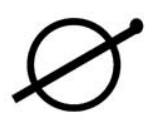

$30^{\circ}$
Table 1. Blind subjects $(n=12)$

\begin{tabular}{|c|c|c|c|c|}
\hline Sex & Age & Handedness & $\begin{array}{l}\text { Age at onset of } \\
\text { blindness (years) }\end{array}$ & Cause of blindness \\
\hline \multicolumn{5}{|c|}{ Congenitally blind subjects $(n=7)$} \\
\hline$F^{*}$ & 31 & $\mathrm{R}$ & 0 & Leber's congenital amaurosis \\
\hline $\mathrm{F}$ & 31 & $\mathrm{R}$ & 0 & Retinitis pigmentosa (from birth) \\
\hline$F^{*}$ & 40 & $\mathrm{R}$ & 0 & Retinitis pigmentosa (from birth) \\
\hline M & 19 & $\mathrm{R}$ & 0 & Congenital malformation \\
\hline$M^{*}$ & 35 & $\mathrm{R}$ & 0 & Leber's congenital amaurosis \\
\hline$M^{*}$ & 42 & $\mathrm{R}-\mathrm{L}$ & 0 & Congenital malformation \\
\hline$M^{*}$ & 62 & $\mathrm{R}$ & 0 & Pigmentary degeneration (from birth) \\
\hline \multicolumn{5}{|c|}{ Postnatally blind subjects $(n=5)$} \\
\hline $\mathrm{F}$ & 28 & $\mathrm{R}$ & 19 & Aniridia-congenital glaucoma \\
\hline$F^{*}$ & 47 & $\mathrm{R}$ & 27 & Degenerative retinitis pigmentosa \\
\hline $\mathrm{F}$ & 54 & $\mathrm{R}$ & 6 & Meningitis \\
\hline $\mathrm{F}$ & 55 & $\mathrm{R}$ & 7 & Retinitis \\
\hline M & 28 & $\mathrm{~L}$ & 23 & Ocular hypertension (optical nerve) \\
\hline
\end{tabular}

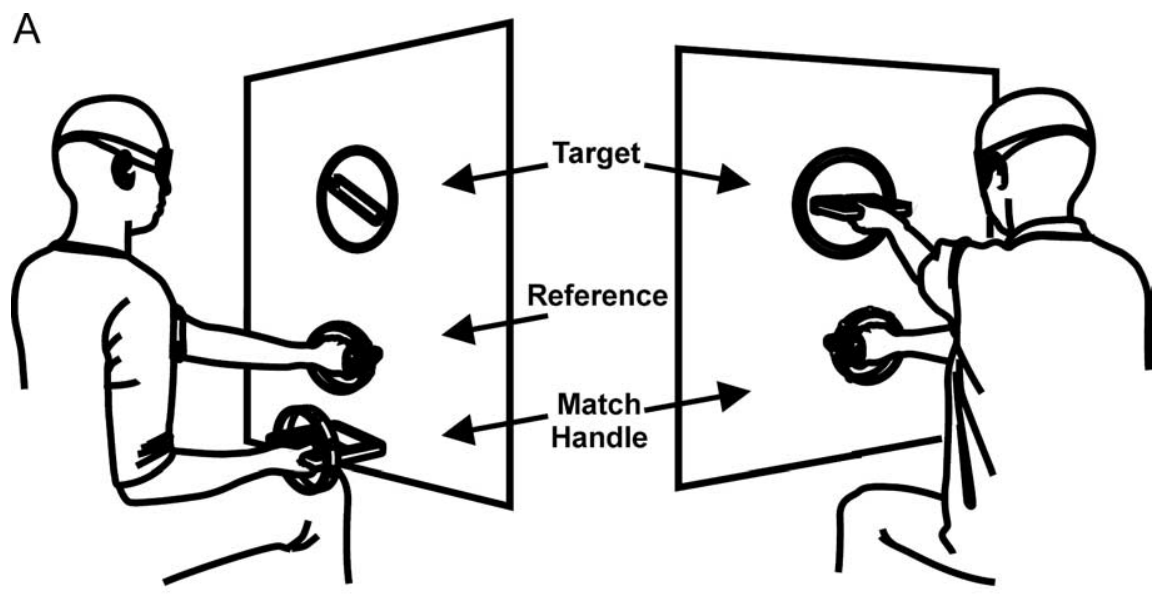

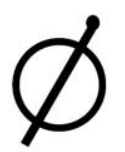

$60^{\circ}$

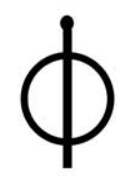

$90^{\circ}$

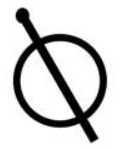

$120^{\circ}$

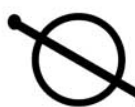

$150^{\circ}$

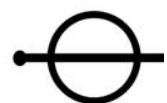

$180^{\circ}$
Figure 1. Schematic representation of the experimental setup. $A$, Subjects had to align the orientation of a rectangular match handle with the orientation of a target. In the letter-posting tasks (left), subjects held the match handle in the right hand and had to try to insert it into the target slot. A reference handle held in the left hand gave information about the target orientation and distance. In the orientation-matching tasks (right), subjects held the match handle in the right hand (bottom) and aligned it with from the back of the panel until it was judged by subjects to be aligned with the target handle. In the active orientation-matching task, the subjects rotated the handle themselves until they judged it to be aligned with the target handle. $\boldsymbol{B}$, Target was fixed in one of six possible orientations $\left(30^{\circ}, 60^{\circ}, 90^{\circ}, 120^{\circ}, 150^{\circ}\right.$, and $\left.180^{\circ}\right)$. Dots, Side of the handle on which the right thumb was positioned to match the orientation of the target. angular handle $(14.5 \mathrm{~cm} \times 2.0 \mathrm{~cm}$; orientation-matching task $)$ or a slot $(16.5 \mathrm{~cm} \times 3.2 \mathrm{~cm}$; letter-posting tasks) that could be fixed in one of six preset orientations $\left(30^{\circ}, 60^{\circ}, 90^{\circ}, 120^{\circ}, 150^{\circ}\right.$, or $180^{\circ}$, proceeding counterclockwise from $0^{\circ}$ at the right) (Fig. $1 B$ ). The target was positioned at eye level and aligned with the body midline, at a comfortable arm-length distance (i.e., at a distance reachable with near full arm extension). Subjects attempted to align the orientation of a rectangular match handle $(14.5 \mathrm{~cm} \times 2.0 \mathrm{~cm})$ with that of the target. Eight infrared-emitting diodes (IREDs) were fixed in a circle around the perimeter of the match handle. The positions of the IREDs were recorded using an Optotrak 3020 motion capture system (Northern Digital) at a sampling frequency of 100 $\mathrm{Hz}$. Rotations of the match handle were made in the counterclockwise 
direction, starting from $0^{\circ}$ orientation (handle horizontal and right wrist and forearm supine, palm up) in each trial.

The spatial orientations of the target (or reference) and match handles were both sensed using only proprioception. Subjects were asked to keep their left hand on the target (or reference) handle and their right hand on the match handle between trials in all tasks. In the orientation-matching task, subjects aligned the match handle (a low-friction bearing-mounted handle) held in their right hand to the same perceived orientation as the target handle in their left hand. In the letter-posting tasks, subjects held onto the lower reference handle (the match handle of the orientationmatching task) with their left hand. The experimenter positioned the lower reference handle into one of the six orientations at the start of each trial to signal to the subjects the orientation of the target slot in that trial, by proprioception. The subjects then reached out and oriented the match handle in their right hand to attempt to insert it into the target slot (letter-posting task 1) or oriented their hand at the start position and then reached out (letter-posting task 2), guided only by proprioceptive input.

Each task comprised a series of trials during which the subjects attempted to align the match handle with the spatial orientation of the target. At the start of each trial, the experimenter set the target at its desired spatial orientation. A complete dataset in each task condition comprised five trials for each of the six target orientations (30 trials in total), in a randomized-block design.

\section{Task order}

All blind $(n=12)$ and normally sighted $(n=18)$ subjects first performed passive and active orientation-matching tasks and letter-posting task 1 (see below). Orientation-matching and letter-posting 1 tasks were performed in a random order within and across subjects. A smaller subset of the same subjects (blind $n=6$; sighted $n=10$ ) subsequently performed letter-posting task 2 . For normally sighted subjects, letter-posting task 2 was done in a separate session on a different day. In contrast, to avoid imposing a second laboratory visit on the blind subjects, the blind subjects performed letter-posting task 2 on the same day as the other tasks, following a break. As the blind subjects only performed the tasks in the no-vision sensory condition, the blind subjects performed all tasks in one visit that lasted $\sim 2 \mathrm{~h}$.

\section{Orientation-matching task}

In the orientation-matching task, subjects aligned the match handle to the target. The target was a handle identical to the match handle. Both handles were mounted on the task panel, with the match handle positioned $30 \mathrm{~cm}$ below the target (Fig. $1 \mathrm{~A}$, right). The match handle rotated freely about the axis perpendicular to the vertical plane of the task panel. Subjects held the target handle with their left hand, and held and aligned the match handle to the same perceived orientation with their right hand. Subjects held onto the match handle with their right hand between trials while the experimenter rotated it back to the starting position $\left(0^{\circ}\right)$ for the next trial. Subjects also held onto the target handle with their left hand between trials while the experimenter rotated it to the new target orientation for the next trial.

Passive orientation-matching task. After setting the desired spatial orientation of the target handle at the start of each trial, the experimenter gave the subject a verbal warning ("Ready ... Go"), and then rotated the match handle smoothly $\left(20.0 \pm 5.0^{\circ} \mathrm{s}\right)$ from the back of the panel, starting at $0^{\circ}$ in each trial, until the subjects reported verbally that it matched the orientation of the target handle. Subjects could give verbal instructions to the experimenter to rotate the match handle back and forth until they were satisfied that it was aligned with the target. The experimenter then recorded the orientation of the match handle for $0.5 \mathrm{~s}$, rotated the match handle back to the starting position $\left(0^{\circ}\right)$, and positioned the target handle at a new orientation for the next trial. The task was always performed by the same experimenter, for all subjects tested. Subjects were instructed to neither assist nor resist the rotational force. Assistive/resistive forces generated by the subjects were easily detected by the experimenter because of the low-friction bearing-mounted handle, which they both held on opposite sides of the task panel. At the moment the experimenter perceived an assistive/resistive force when rotating the handle, the trial was aborted and then restarted from the initial start position, with a further verbal instruction to the subject not to intervene. This happened very infrequently.

Active orientation-matching task. Following a verbal command from the experimenter ("Ready... Go"), the subjects aligned the match handle to the orientation of the target handle by actively rotating their right wrist and forearm at a comfortable speed, starting at $0^{\circ}$ (hand supinated). Subjects could adjust the orientation by rotating the match handle back and forth until they reported verbally that it was aligned with the target. The experimenter then recorded the orientation of the match handle for $0.5 \mathrm{~s}$. Subjects held onto the match handle between trials while the experimenter rotated it back to the starting position $\left(0^{\circ}\right)$ and positioned the target handle at a new orientation for the next trial.

\section{Letter-posting task 1: orient hand while reaching to the target}

In letter-posting task 1 , a target slot replaced the target handle. The match handle was a freely moving rectangular handle, instrumented with eight IREDs, that was of identical construction to the match handle in the orientation-matching task. At the start of each trial, subjects held the match handle in their supinated right hand with their arm semiflexed at the side of their body (Fig. 1 A, left) while the experimenter set both the target slot and lower handle (reference handle held by the subjects in their left hand) at the desired orientation. After a verbal command ("Ready ... Go"), the subjects reached out to the target. Subjects were instructed to reach out and to simultaneously rotate the handle in a single continuous motion at a quick but comfortable speed to try to insert the match handle into the target slot, without attempting to correct the handle position or orientation at the end of the reach.

Because the target slot was only slightly larger than the match handle, the subjects attempted to complete the rotation of the handle before it arrived at the target panel. However, it was difficult to insert the handle into the slot in one rapid continuous motion without visual input. As a result, in many trials, the subjects contacted the task panel with the handle instead of inserting the match handle into the target slot. However, this did not seriously perturb their performance (see GosselinKessiby et al., 2008). Whether or not they succeeded in inserting the match handle into the slot, the subjects were instructed to hold that final position until told by the experimenter to return their arm to the start position. In the letter-posting tasks, match handle coordinates were recorded continuously for $4 \mathrm{~s}$, starting from the "Go" command. At the end of the $4 \mathrm{~s}$, the experimenter told the subjects to return their arm to the start position and to rotate their hand back to the starting supine orientation to begin the next trial.

\section{Letter-posting task 2: orient hand and then reach to the target}

Letter-posting task 2 was designed to assess whether hand orientation would remain constant or would change in some systematic way during reach to the target, if the subjects perceived that their hand was already at the final desired orientation before beginning to reach. As in letterposting task 1 , subjects held the rectangular match handle in their supinated right hand with their arm in semiflexion beside their body at the start of each trial. However, in letter-posting task 2, subjects were instructed to first rotate their wrist and forearm to align the match handle with the target slot while keeping their arm at their side. They could correct their hand orientation by rotating the handle back and forth until they reported verbally that they perceived that it was aligned. They were then given a verbal command by the experimenter ("Ready ... Go") to reach out to the target. The subjects were instructed to reach out to the target slot at a comfortable speed, and to try not to change their initial hand orientation during the reach. At the end of each reach, the subjects held their final hand and arm position until told by the experimenter to return their arm and hand to the start position to begin the next trial.

\section{Data analysis}

In the orientation-matching task, match handle orientation was measured by recording the spatial coordinates of IREDs fixed on the match handle. The angle of rotation of the handle was calculated by simple trigonometry using the $(x, y, z)$ coordinates of the observable IREDs on the perimeter of the match handle. Final orientation was the mean ori- 
entation computed over a sampling period of $0.5 \mathrm{~s}$ taken after the subjects had reported that the match handle was aligned with the target handle.

In the letter-posting tasks, the full threedimensional (3D) spatial orientation of the match handle was determined from the $(x, y, z)$ coordinates of the observable IREDs on the perimeter of the handle. Hand orientation was defined as the projection of the $3 \mathrm{D}$ orientation of the handle onto the $2 \mathrm{D}$ vertical (frontal) plane of the target panel. Reach onset was defined as the first time the 3D hand transport velocity exceeded $3 \%$ of peak 3D hand transport velocity and remained above that value until peak velocity was attained. Reach offset was defined as the first time the transport velocity toward the target panel decreased to $<3 \%$ of peak velocity. For the letter-posting tasks, final hand orientation was determined by calculating the mean orientation during the $50 \mathrm{~ms}$ immediately preceding the detected reach offset (Dyde and Milner, 2002). This time period was used to avoid confounding the measured hand orientation with any passive mechanical rotation of the handle caused by contact with the task panel (Gosselin-Kessiby et al., 2008). The initial orientation in letter-posting task 2 corresponded to the mean handle orientation during the 50 $\mathrm{ms}$ immediately preceding the detected reach onset.

\section{Performance measures}

To compare the accuracy and precision of the spatial orientation of the match handle in the different tasks, constant, absolute, and variable errors were analyzed for each target orientation. The match handle orientation error in each trial was defined as the angular difference between the orientation of the target and the final match handle orientation, as well as the initial match handle orientation in letter-posting task 2 . For constant error, a positive orientation error occurred when the subject made a counterclockwise rotation of the match handle past the actual orientation of the target, whereas negative errors occurred when the match handle did not attain the target orientation. Mean constant error at each target in each dataset for each subject was the mean of the signed values of the orientation errors for the five trials at that target orientation, and provides a measure of any constant bias (accuracy) in the estimates of match handle orientation for each target orientation. Mean absolute error was the mean of the absolute (unsigned) values of the orientation errors and provides a measure of the overall size of orientation errors for each target. Mean variable error was defined as the mean value of the difference between the final orientation of the match handle in each trial from the mean of the final orientation of the match handle for the five trials at a given target orientation (as well for the initial match handle orientation in letter-posting task 2), and provides a measure of the dispersion (precision) of the final orientations about the mean constant error bias in performance at each target orientation.

\section{Statistical analysis}

Constant, absolute, and variable errors for different target orientations were compared in different tasks using two-way or three-way ANOVAs. Peak velocities and movement duration for different target orientations in letter-posting task 1 were compared using one-way ANOVAs. Post hoc pairwise comparisons were made using Tukey honestly significant difference (HSD) analyses (Statistica, Statsoft). For all ANOVAs and Tukey HSD analyses, the threshold for statistical significance was set at 0.05 .

When comparing congenitally blind and postnatally blind subject groups, or blind and blindfolded normally sighted subject groups, this study used a within-subject repeated-measures design, with one between factor (group) and two within factors (task and target orientation; or time and target orientation). For conciseness, only main effects and interactions including group factor (congenital vs acquired blindness, and blind vs sighted subjects), task factor (orientation-matching vs letterposting task 1), or time factor (letter-posting task 2; initial vs final hand orientation) are reported.

\section{Results}

We present here the findings from seven congenitally blind and five postnatally blind subjects (Table 1). We also present quantitative comparisons of the findings from the blind subjects with those from 18 age-matched normally sighted subjects who performed the tasks while blindfolded, which have been reported previously (Gosselin-Kessiby et al., 2008).

All blind subjects tested except two were right handed. Statistical analysis using only the 10 right-handed blind subjects produced main statistical results similar to those reported here for all 12 subjects combined (data not shown). This indicated that handedness did not affect the performance of blind subjects in these tasks. Moreover, the populations of blind and normally sighted subjects had a broad range of ages, but statistical tests (three-way ANOVAs including age as a factor; three age groups: $18-32$ years, 33-49 years, and 50-64 years) found no significant age-related differences in the main results reported here for the blind subjects alone or for both blind and normally sighted subjects together, indicating that subject age did not influence overall task performance $(p>0.05$; data not shown).

\section{Kinematics of letter-posting task 1 (orient hand while reaching to the target)}

The overall pattern of velocity profiles of hand transport (reach) and hand rotation was similar across subjects and between groups. Figure 2 presents the mean velocity profiles of hand transport toward the target panel and of hand rotation, for a representative blind subject. The hand began to rotate at the onset of hand transport, and the peak velocity of rotation increased 


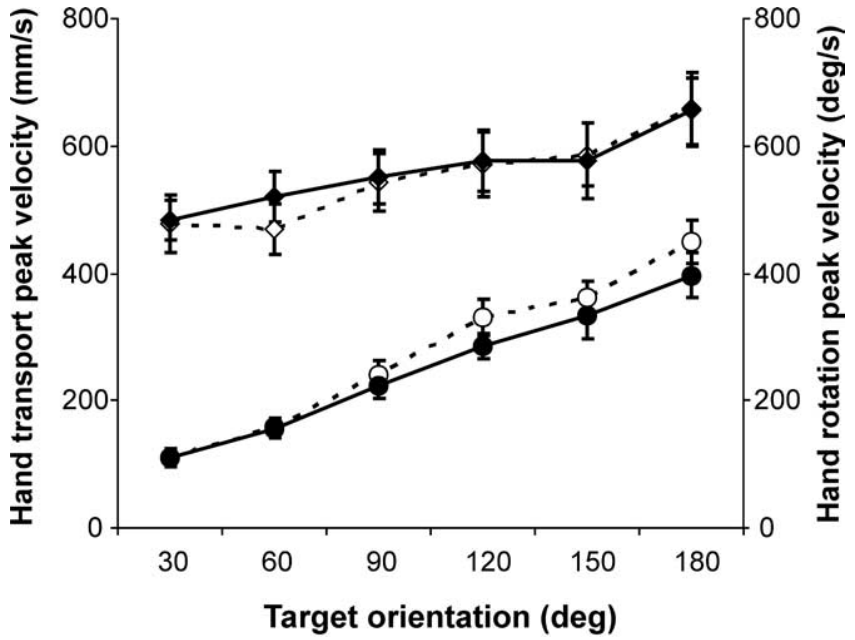

Figure 3. Mean peak velocities for hand transport toward the panel (diamonds) and hand rotation (circles) across all blind ( $n=12$; filled symbols) and blindfolded normally sighted ( $n=$ 18; open symbols) subjects for movements aimed to the six target orientations in the letterposting task 1 . Axes represent the hand transport velocity (in millimeters per second) and the hand rotation velocity (in degrees per second) as a function of target orientation (in degrees). Error bars represent SEM.

with the degree of hand rotation required from the initial supine orientation. These results indicate that letter-posting task 1 was performed with a continuous and simultaneous motion of the arm and hand. Peak rotation velocity tended to occur earlier than the peak of hand transport for all six target orientations [mean difference between peak rotation and peak transport across all blind subjects for all target orientations was $0.05 \pm 0.02 \mathrm{~s}$; not different from blindfolded normally sighted: $0.04 \pm 0.01 \mathrm{~s}(p>$ $0.05)]$. The hand rotations in blind subjects also ended slightly earlier than hand transport, indicating that the hand was near its final orientation shortly before the hand reached the target panel. A similar trend had been reported for blindfolded normally sighted subjects (Gosselin-Kessiby et al., 2008).

Peak velocities were affected by target orientation. Figure 3 presents the mean peak velocity for hand rotation and hand transport toward the target panel, in blind $(n=12)$ and blindfolded normally sighted $(n=18)$ subjects tested in letter-posting task 1 . Blind subjects showed a statistically significant effect of target orientation on the peak velocity of both hand rotation (one-way ANOVA, $p<0.05 ; F_{(5,55)}=25.12$ ) and hand transport (one-way ANOVA, $p<0.05 ; F_{(5,55)}=10.51$ ). The greater the required degree of rotation of the hand during the reach, the greater the peak wrist rotation velocity and the greater the peak transport velocity directed toward the target panel in the blind subjects. Blindfolded normally sighted subjects showed very similar trends, and there was no difference between the groups for both hand rotation peak velocity (two-way ANOVA, $p>0.05$; $F_{(1,28)}=0.72$ ) and hand transport peak velocity (two-way ANOVA, $\left.p>0.05 ; F_{(1,28)}=0.02\right)$. Similarly, both groups showed a strong effect of target orientation on the peak velocity of both hand rotation $\left(F_{(5,140)}=112.95 ; p<0.05\right)$ and hand transport $\left(F_{(5,140)}=33.21 ; p<0.05\right)$. The greater the required degree of rotation of the hand during the reach, the greater the peak wrist rotation velocity and the greater the peak transport velocity directed toward the target panel. These findings indicate that the coordination between hand rotation and transport was statistically identical in blind and blindfolded normally sighted subjects.

Although blind subjects showed a statistically significant main effect of target orientation on the duration of hand transport (one-way ANOVA, $p<0.05 ; F_{(5,55)}=2.46$ ), no post hoc tests reached the significance level $(p>0.05)$. The mean duration of hand transport for blind subjects was $1.31 \mathrm{~s}$. In contrast, the mean duration of hand transport in blindfolded normally sighted subjects was $1.08 \mathrm{~s}$. A two-way ANOVA ( 2 groups $\times 6$ target orientations) revealed a main effect of group on hand transport duration, with blindfolded normally sighted subjects having significantly shorter transport durations than blind subjects $(p<$ $\left.0.05 ; F_{(1,28)}=5.30\right)$.

\section{Letter-posting task 1 versus orientation-matching tasks: blind subjects}

Figure 4 presents the final orientations of individual trials in a representative blind subject, in the passive orientation-matching task and letter-posting task 1 . The final hand orientation was more accurate in letter-posting task 1 than in the passive orientation-matching task.

The single subject of Figure 4 displayed most of the trends of the entire group of blind subjects $(n=12)$ (Fig. 5). Those general trends were supported by statistical analyses. Separate two-way ANOVAs ( 3 tasks $\times 6$ target orientations) were performed on the constant, absolute, and variable errors made by blind subjects in the passive and active orientation-matching tasks and letterposting task 1 .

For constant errors, a significant main effect of task $(p<0.05$; $F_{(2,22)}=34.24$; mean error in passive orientation-matching, active orientation-matching, and letter-posting tasks, respectively: $-16.05^{\circ},-12.22^{\circ}$, and $\left.-0.90^{\circ}\right)$ and a significant main effect of target orientation $\left(p<0.05 ; F_{(5,55)}=11.53\right.$; mean error for $30^{\circ}$ to $180^{\circ}$, respectively: $-7.03^{\circ},-13.78^{\circ},-4.83^{\circ},-4.35^{\circ},-13.46^{\circ}$, and $\left.-14.88^{\circ}\right)$. Post hoc analyses revealed no significant difference between the passive and active orientation-matching tasks $(p>$ $0.05)$, and significantly smaller constant errors in letter-posting task 1 than in the passive and active orientation-matching tasks $(p<0.05)$. Post hoc analyses also revealed significantly smaller constant error for $30^{\circ}, 90^{\circ}$, and $120^{\circ}$ compared with $60^{\circ}, 150^{\circ}$, and $180^{\circ}(p<0.05)$.

Similar results were observed for absolute errors. There were significant main effects of task $\left(p<0.05 ; F_{(2,22)}=10.54\right.$; mean passive orientation-matching, active orientation-matching, and letter-posting tasks, respectively: $17.34^{\circ}, 14.21^{\circ}$, and $10.00^{\circ}$ ) and of target orientation $\left(p<0.05 ; F_{(5,55)}=6.27\right)$, as well as a significant interaction between these two factors $\left(p<0.05 ; F_{(10,280)}=\right.$ 9.23). Post hoc tests revealed no significant difference between the passive and active orientation-matching tasks for all target orientations $(p>0.05)$. However, post hoc tests showed significantly smaller absolute errors in letter-posting task 1 than in the passive orientation-matching task for the largest target orientations $150^{\circ}$ and $180^{\circ}$, and than in the active orientation-matching task for the largest target orientation $180^{\circ}(p<0.05)$.

In contrast to constant and absolute errors, no main effect of task was observed for variable errors $\left(p>0.05 ; F_{(2,22)}=1.34\right)$. Nevertheless, there were a significant main effect of target orientation $\left(p<0.05 ; F_{(5,55)}=3.29\right)$. Post hoc comparisons revealed significant larger variable error for $60^{\circ}$ compared with $30^{\circ}$ and $120^{\circ}(p<0.05)$.

In summary, the ANOVA results showed that the performance of blind subjects in the active orientation-matching task was very similar to that in the passive orientation-matching task, but different from that in letter-posting task 1, especially for larger target orientations. 


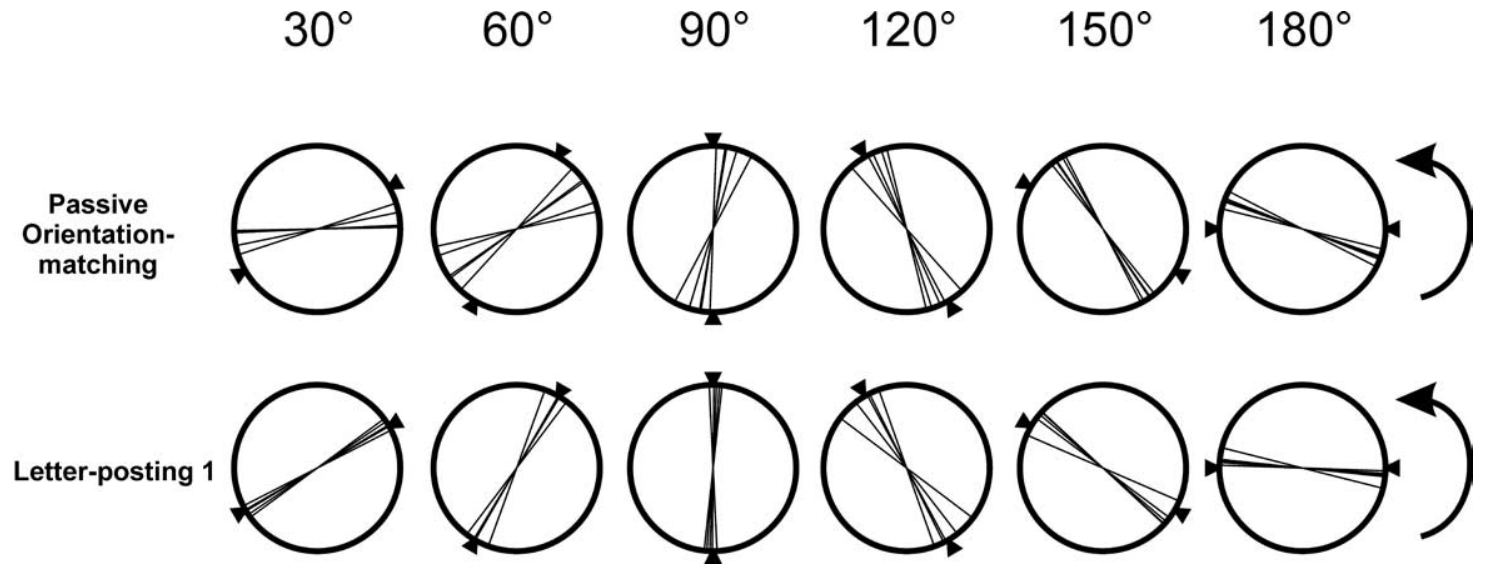

Figure 4. Orientations of the match handle relative to the target in a representative blind subject, across individual trials aimed to six target orientations in the passive orientation-matching task and letter-posting task 1. Each of the circles represents the trials for one target orientation. Arrowheads on the circumference of each circle indicate the desired target orientation. The lines inside each circle represent the final hand orientation for five individual trials at each target orientation. Arrows at the right represent the counterclockwise rotation of the hand from the starting position $\left(0^{\circ}\right)$.

Letter-posting task 1 versus orientation-matching tasks: congenitally blind versus postnatally blind subjects

We compared the performance of congenitally $(n=7)$ and postnatally $(n=5)$ blind subjects (Table 1$)$ to evaluate whether prior visual experience influenced the final hand orientation in orientation-matching and letter-posting tasks. Separate threeway ANOVAs ( 2 groups of blind subjects $\times 3$ tasks $\times 6$ target orientations) were performed on the constant, absolute, and variable errors. For purpose of conciseness, only analyses including the group factor are reported. For all constant, absolute, and variable errors, no significant differences were observed between the congenitally and postnatally blind subjects.

For constant errors, there was no main effect of group $(p>$ $\left.0.05 ; F_{(1,10)}=0.02\right)$, but there was a significant three-way interaction between all three factors $\left(p<0.05 ; F_{(10,100)}=2.02\right)$. However, no post hoc tests reached significance, suggesting that performance was not different in congenitally and postnatally blind subjects.

Similar results were observed for absolute errors. There was no main effect of group $\left(p>0.05 ; F_{(1,10)}=0.283\right)$, but there was a significant three-way interaction between the three factors $(p<$ $\left.0.05 ; F_{(10,100)}=3.00\right)$. Post hoc tests revealed a single case of a significant difference at the horizontal orientation $\left(180^{\circ}\right)$ in the active orientation-matching task (mean error congenital: $14.32^{\circ}$; mean error postnatal: $28.15^{\circ}$ ).

For variable errors, there was no main effect of group $(p>$ $\left.0.05 ; F_{(1,10)}=0.169\right)$, and no significant interaction effects $(p>$ $0.05)$.

In summary, the ANOVA results confirmed that the performance of congenitally $(n=7)$ and postnatally $(n=5)$ blind subjects was essentially identical across tasks and target orientations.

Letter-posting task 1 versus orientation-matching tasks: blind versus blindfolded normally sighted subjects

The performance of the blind subjects was strikingly similar to that of the normally sighted but blindfolded subjects. Figure 5 presents the mean constant, absolute, and variable errors of hand orientation in blind $(n=12)$ and blindfolded normally sighted subjects $(n=18)$ in the passive and active orientation-matching tasks and in letter-posting task 1. Accuracy and precision of hand orientation varied across tasks in a similar manner in both groups. The mean constant and absolute orientation errors were on average smallest in letter-posting task 1, largest in the passive orientation-matching task, and intermediate in the active orientation-matching task (Fig. 5, first columns). This indicated that in both normally sighted and blind subjects, the subjects' ability to align their hand orientation to a target at the end of a single continuous reach-and-orient movement without vision of the hand and target was better than their perceptual ability to align the two handles using proprioception in the orientationmatching task, even when given ample time to adjust and correct the match handle orientation in the latter task. The magnitude of variable errors was fairly similar across target orientations and tasks (Fig. 5, third column).

Those general trends were supported by statistical analyses. Separate three-way ANOVAs ( 2 groups $\times 3$ tasks $\times 6$ target orientations) were performed on the constant, absolute, and variable errors made by subjects in the passive and active orientationmatching tasks and letter-posting task 1 . For constant errors, no main effect of group was observed $\left(p>0.05 ; F_{(1,28)}=0.001\right)$. There were a significant main effect of task $\left(p<0.05 ; F_{(2,56)}=\right.$ 76.44; mean error in passive orientation-matching, active orientation-matching, and letter-posting tasks, respectively: $-14.79^{\circ},-12.31^{\circ}$, and $\left.-1.96^{\circ}\right)$ and a significant main effect of target orientation $\left(p<0.05 ; F_{(5,140)}=26.90\right)$, as well as a twoway interaction between those two factors $\left(p<0.05 ; F_{(10,280)}=\right.$ 5.51). Post hoc analyses revealed no significant difference between the passive and active orientation-matching tasks for all target orientations $(p>0.05)$, significantly smaller constant errors in letter-posting task 1 than in the passive orientation-matching task for all target orientations $(p<0.05)$, and significantly smaller constant errors in letter-posting task 1 than in the active orientation-matching task for all target orientations except $90^{\circ}$ $(p<0.05)$.

Similar results were observed for absolute errors. No main effect of group was observed $\left(p>0.05 ; F_{(1,28)}=0.51\right)$. There were significant main effects of task $\left(p<0.05 ; F_{(2,56)}=21.78\right.$; mean passive orientation-matching, active orientationmatching, and letter-posting tasks, respectively: $16.04^{\circ}, 14.03^{\circ}$, and $\left.9.84^{\circ}\right)$ and of target orientation $\left(p<0.05 ; F_{(5,140)}=15.61\right)$, as well as a significant interaction between these two factors $(p<$ $\left.0.05 ; F_{(10,280)}=9.23\right)$. Post hoc tests revealed no significant difference between the passive and active orientation-matching tasks for all target orientations $(p>0.05)$. However, post hoc tests showed significantly smaller absolute errors in letter-posting task 
Mean constant error Mean absolute error Mean variable error
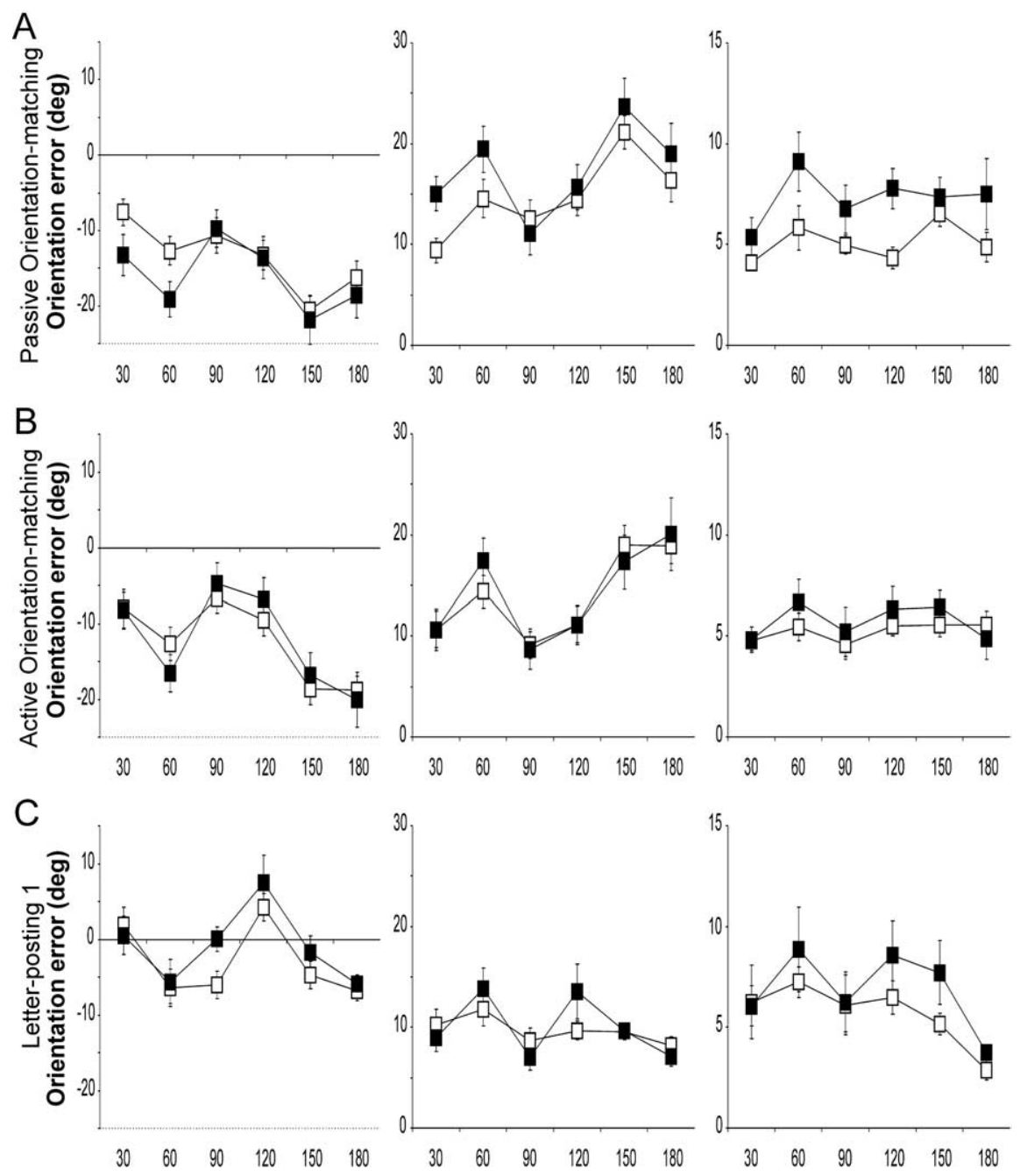

Target orientation $(\mathrm{deg})$
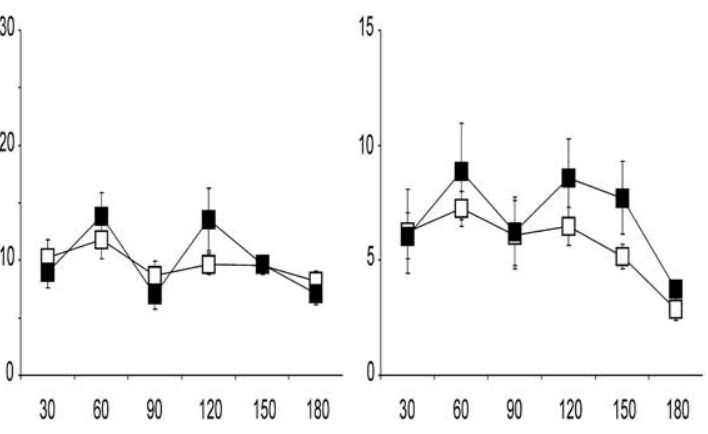

Target orientation (deg)

Figure 5. Mean errors in orientation across blind ( $n=12$; filled squares) and blindfolded normally sighted subjects $(n=18$; open squares), in orientation-matching tasks and letter-posting task 1 . Mean of constant, absolute, and variable errors are shown in different columns. Tasks are presented in different rows ( $\boldsymbol{A}$ : passive orientation-matching task; $\boldsymbol{B}$ : active orientation-matching task; $C$ : letter-posting task 1). Error bars represent SEM. Data from blindfolded normally sighted subjects have been reported previously (Gosselin-Kessiby et al., 2008).

1 than in both the passive orientation-matching task and the active orientation-matching task for the largest target orientations, $150^{\circ}$ and $180^{\circ}(p<0.05)$.

As for constant and absolute errors, no main effect of group was observed for variable errors $\left(p>0.05 ; F_{(1,28)}=3.70\right)$. In contrast to constant and absolute errors, however, no main effect of task was observed for variable errors $\left(p>0.05 ; F_{(2,56)}=1.12\right)$. There were a significant main effect of target orientation $(p<$ $\left.0.05 ; F_{(5,140)}=5.45\right)$ and a significant two-way interaction between task and target orientation $\left(p<0.05 ; F_{(10,280)}=2.62\right)$. Post hoc comparisons revealed no significant difference between the passive and active orientation-matching tasks for all target orientations $(p>0.05)$, significantly smaller variable errors in the letter-posting task 1 than in the passive orientation-matching task only for the largest target orientation $180^{\circ}(p<0.05)$, and no significant difference between the letter-posting task 1 and the active orientation-matching task for all target orientations ( $p>$ 0.05).

In summary, the ANOVA results confirmed that the performance of blind and blindfolded normally sighted subjects was similar, and that the performance of both groups in the active orientation-matching task was more similar to that in the passive orientation-matching task than in letterposting task 1 .

Letter-posting task 2 in blind subjects: initial versus final hand orientation In letter-posting task 1 , the blind subjects reached out to the target and also actively rotated their wrist and forearm to align the match handle to the target. The better accuracy of the blind subjects in letterposting task 1 than in the passive orientation-matching task may have been due mainly to one or the other of those two movement components. However, as the performance in the passive and active orientation-matching tasks was not significantly different, these findings suggested that active hand rotation per se had a relatively minor effect on performance. This suggested that the act of reaching accounted for most of the improvement in performance of the blind subjects in letterposting task 1 compared with the orientation-matching tasks.

To further investigate the effect of reaching on hand orientation, we subsequently tested the performance of a subset of the same blind and sighted subjects in letter-posting task 2 , in which subjects attempted to align the match handle to the target before reaching and then to maintain the initial orientation of the match hand as they reached to the target. Figure 6 presents the initial and final orientations of individual trials in a representative blind subject in letter-posting task 2 . The orientation errors tended to be smaller at the end of the reaching movement than before movement onset, despite the instruction to not change the hand orientation during the reach.

The single subject of Figure 6 displayed most of the trends of the entire group of blind subjects $(n=6)$ (Fig. 7). These trends were supported by statistical analyses. Separate two-way ANOVAs ( 2 times $\times 6$ target orientations) were performed on the constant, absolute, and variable initial and final errors made by blind subjects.

For constant errors, there were significant main effects of time (initial vs final hand orientation, $p<0.05 ; F_{(1,5)}=29.38$; mean initial and final error, respectively: $-14.64^{\circ}$ and $\left.-5.01^{\circ}\right)$ and of target orientation $\left(p<0.05 ; F_{(5,25)}=2.74\right)$. Post hoc tests showed that constant errors in hand orientation were significantly smaller at the endpoint than before the onset of reaching ( $p<$ $0.05)$. However, post hoc comparisons revealed no significant difference between target orientations ( $p>0.05)$.

For absolute errors, there were significant main effects of time (initial vs final, $p<0.05 ; F_{(1,5)}=16.18$; mean initial and final error, respectively: $15.10^{\circ}$ and $9.98^{\circ}$ ) with smaller absolute errors 


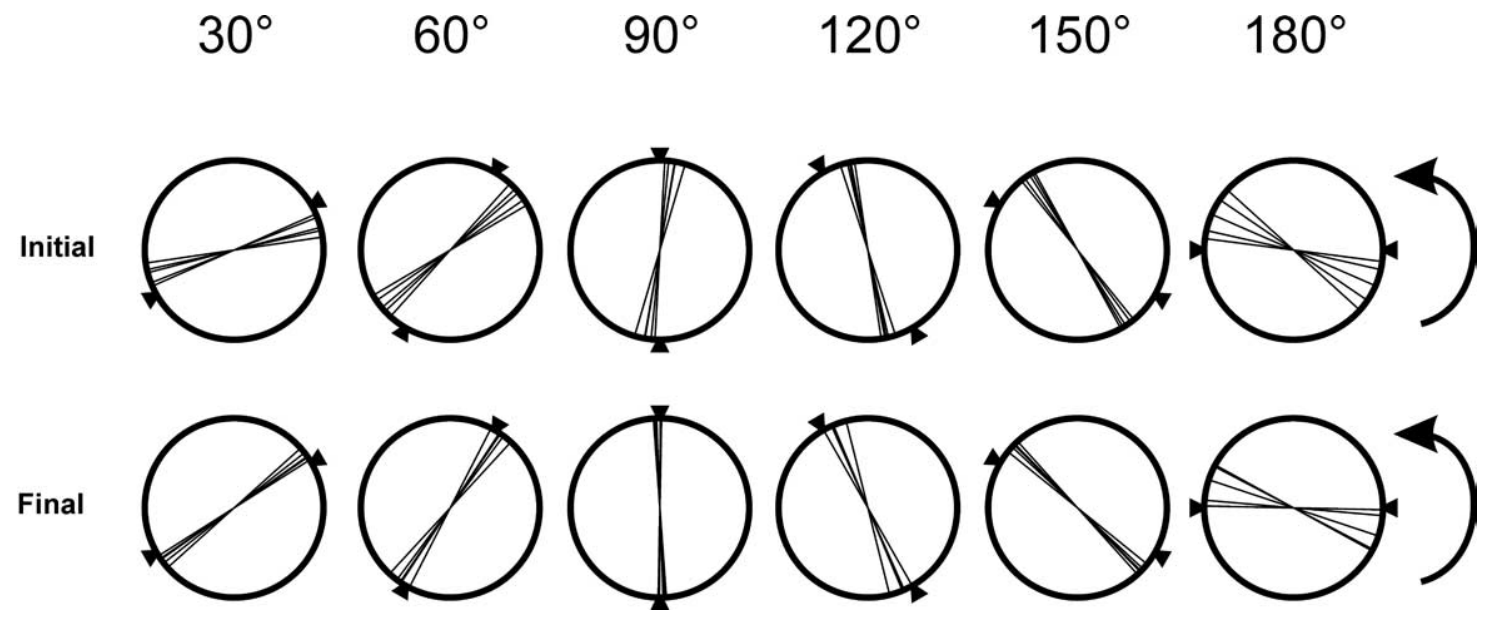

Figure 6. Initial and final orientations of the match handle relative to the target in a representative blind subject, across individual trials aimed to six target orientations in letter-posting task 2. The format is identical to that of Figure 4.

at the end of reaching than before movement onset, but no main effect of target orientation $\left(p>0.05 ; F_{(5,25)}=0.86\right)$. There was a significant time-by-targetorientation two-way interaction $(p<$ $\left.0.05 ; F_{(5,25)}=2.81\right)$. Post hoc tests showed that significant differences between initial and final hand orientation were found at target orientations $60^{\circ}, 150^{\circ}$, and $180^{\circ}$ $(p<0.05)$.

For variable errors, no main effect of time $\left(p>0.05 ; F_{(1,5)}=0.35\right)$, no main effect of target orientation $(p>0.05$; $\left.F_{(5,25)}=0.36\right)$, and no significant interactions were found $(p>0.05)$.

In summary, the ANOVA results confirmed that orientation errors tended to be smaller at the end of the reaching movement than before movement onset in blind subjects, even though they were instructed not to change hand orientation during the reach.

Letter-posting task 2: blind versus blindfolded normally sighted subjects Figure 7 presents the mean constant, absolute, and variable errors of hand orientation before and after the reach motion in blind $(n=6)$ and blindfolded normally sighted $(n=10)$ subjects in letter-posting task 2. Both groups showed strikingly similar patterns of constant errors across target orientations. Furthermore, both groups of subjects tended to show a systematic underrotation of the hand before reaching, which was more pronounced in the blind subjects than in the normally sighted subjects. The mean constant and absolute orientation errors tended to be smaller at the end of the reach than before the reach, in both groups (Fig. 7, first columns). This indicated that in both blind and sighted subjects, the subjects' ability to align their hand orientation to a target was generally better at the end of a single reaching movement than before the reach. The magnitude of variable errors was fairly similar before and after the reach for each target orientation in both blind and sighted subjects (Fig. 7, third column).
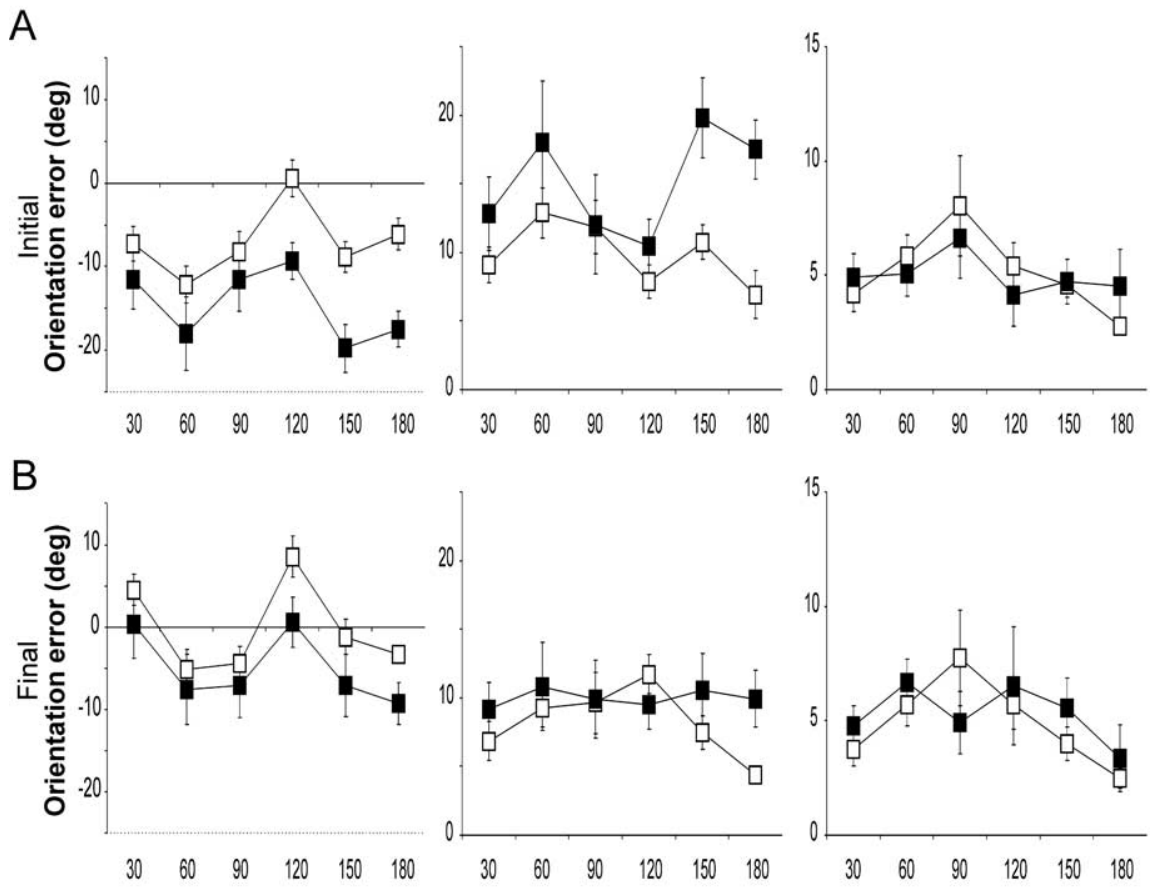

Figure 7. Mean errors in orientation for blind ( $n=6$; filled squares) and blindfolded normally sighted subjects ( $n=10$; open squares), before (initial) and after (final) the reach motion in letter-posting task 2 . The format is similar to that of Figure 5. Data from blindfolded normally sighted subjects have been reported previously (Gosselin-Kessiby et al., 2008).

Most of these trends were supported by statistical analyses. Separate three-way ANOVAs $(2$ groups $\times 2$ times $\times 6$ target orientations) were performed on the constant, absolute, and variable initial and final errors made by subjects. For constant errors, there were significant main effects of group $\left(p<0.05 ; F_{(1,14)}=\right.$ 7.25; mean error blind: $-9.82^{\circ}$; mean error sighted: $\left.-3.57^{\circ}\right)$, of time (initial vs final hand orientation $p<0.05 ; F_{(1,14)}=43.21$; mean initial and final error, respectively: $-10.81^{\circ}$ and $-2.58^{\circ}$ ), and of target orientation $\left(p<0.05 ; F_{(5,70)}=9.17\right)$. There was a significant two-way interaction between time and target orientation $\left(p<0.05 ; F_{(5,70)}=6.08\right)$. Post hoc tests showed that constant 
errors in hand orientation were significantly smaller at the endpoint than before the onset of reaching movements for all target orientations $(p<0.05)$.

For absolute errors, there were significant main effects of both group $\left(p<0.05 ; F_{(1,14)}=5.53\right.$; mean error in blind and sighted, respectively: $12.542^{\circ}$ and $9.053^{\circ}$ ) and time (initial vs final, $p<$ $0.05 ; F_{(1,14)}=22.504$; mean initial and final error, respectively: $12.50^{\circ}$ and $\left.9.10^{\circ}\right)$, but no main effect of target orientation $(p>$ $\left.0.05 ; F_{(5,70)}=1.41\right)$. There was a significant group-by-time twoway interaction $\left(p<0.05 ; F_{(1,14)}=5.81\right.$; mean initial and final errors in blind: $15.10^{\circ}$ and $9.98^{\circ}$; mean initial and final error in blindfolded sighted: $9.89^{\circ}$ and $8.22^{\circ}$ ). Post hoc comparisons revealed that the initial absolute error was significantly larger in blind than in blindfolded sighted subjects $(p<0.05)$, but that final error was not significantly different in either group $(p>$ $0.05)$. There was also a significant time-by-target-orientation two-way interaction $\left(p<0.05 ; F_{(5,70)}=5.27\right)$, with smaller absolute errors at the end of reaching than before movement onset. Post hoc tests showed that significant differences between initial and final hand orientation were found at target orientations $60^{\circ}$, $150^{\circ}$, and $180^{\circ}(p<0.05)$.

For variable errors, there was only a significant main effect of target orientation $\left(p<0.05 ; F_{(5,70)}=2.4046\right)$. No main effect of group $\left(p>0.05 ; F_{(1,14)}=0.0193\right)$, no main effect of time $(p>$ $\left.0.05 ; F_{(1,14)}=0.0143\right)$, and no significant interactions were found $(p>0.05)$.

In summary, the ANOVA analysis showed that performance of blind and blindfolded normally sighted subjects showed several similarities. Both groups showed strikingly similar patterns of initial and final constant errors across target orientations. Furthermore, even though blind subjects showed larger initial underrotations than blindfolded sighted subjects, both groups showed similar final absolute errors. This indicated that the ability of blind and blindfolded sighted subjects to align their hand orientation to a target was better at the end of a single reaching movement than before the reach and that the size of absolute errors of final hand orientations about the desired target orientation was similar in blind and blindfolded sighted subjects after the reach.

\section{Discussion}

This is the first study, to our knowledge, of the perception of hand orientation and the control of reach-and-orient movements in blind subjects. When blind subjects attempted to align their right hand to the target in the orientation-matching task, they tended to underrotate their hand, whether it was rotated passively or actively. Blind subjects also tended to reduce the final hand orientation errors at the end of a reaching movement. This suggests that blind subjects made on-line adjustments of hand orientation during reaching to stationary targets. Almost no differences were found between congenitally and postnatally blind subjects, and proprioceptive perception of hand orientation was no better in blind subjects than in blindfolded normally sighted subjects. These observations suggest that visual experience is not necessary for the appropriate patterning of reach-and-orient movements or for on-line adjustments of hand orientation during movement.

\section{Performance of blind versus blindfolded normally sighted subjects}

A striking finding of this study was how similar blind and blindfolded normally sighted subjects performed in these tasks. They showed similar global trends in the different tasks, and similar patterns of errors as a function of target orientation in all tasks.

The performance of blind subjects is similar to that of sighted subjects in many tasks (Heller, 1989; Heller and Kennedy, 1990; Castiello et al., 1993; Sergio and Scott, 1998; Sunanto and Nakata, 1998; Grant et al., 2000; Heller et al., 2002b; Vanlierde and Wanet-Defalque, 2004). In contrast, other studies reported that blind subjects outperformed sighted subjects under certain conditions (Rossetti et al., 1996; Van Boven et al., 2000; Goldreich and Kanics, 2003; Gaunet and Rossetti, 2006; Alary et al., 2008). Thus, there is no consensus on the sensorimotor performance of blind subjects compared with normally sighted subjects.

It may seem surprising that blind subjects in this and other studies did not demonstrate an enhanced ability to use proprioception to perceive or guide their actions, compared with normally sighted subjects. Blind subjects must rely exclusively on proprioceptive and tactile inputs to guide their arm and hand movements, whereas normally sighted subjects would intuitively appear to rely mainly on visual feedback in most everyday situations (van Beers et al., 1999, 2002; Ernst and Banks, 2002; Saunders and Knill, 2003, 2004, 2005; Sober and Sabes, 2003, 2005). Nevertheless, our findings indicate that normally sighted subjects perform as well as blind subjects in these tasks when deprived of vision. This suggests that in contrast to intuitive impressions, normally sighted subjects can use proprioceptive input alone to guide their performance as efficiently as blind subjects, who have had a lifetime of experience performing sensorimotor tasks without visual guidance.

\section{Proprioceptive integration for perception, action, and on-line control}

It is now widely accepted that a dorsal "action" stream processes visual information for the guidance of voluntary actions (Goodale and Milner, 1992; Milner and Goodale, 2008). The posterior parietal cortex (PPC) contains a population of neurons implicated in the control of the configuration and orientation of the hand during active reach and grasping (Sakata et al., 1997; Murata et al., 2000). Observations from optic ataxic patients (Pisella et al., 2000; Gréa et al., 2002) and from transcranial magnetic stimulation (Desmurget et al., 1999; Tunik et al., 2005; Rice et al., 2006) and imaging (Culham et al., 2003; Frey et al., 2005; Tunik et al., 2008) studies suggested that one dorsal stream function is an automatic vision-based on-line error-correction mechanism that involves the PPC (Desmurget and Grafton, 2000; Glover, 2004; Buneo and Andersen, 2006; Iacoboni, 2006).

It has been proposed recently that a corresponding distinction between perceptual and action systems might exist in the somatosensory system (Dijkerman and de Haan, 2007). Imaging studies have reported an activation of "dorsal stream" components in PPC during motor actions guided by proprioceptive kinesthetic inputs (Binkofski et al., 1999; Darling et al., 2007; Fiehler et al., 2008, 2009).

Consistent with this dissociation, we found previously that blindfolded normally sighted subjects show different patterns of final hand orientation errors during a perceptual orientationmatching task versus a letter-posting task performed under proprioceptive guidance (Gosselin-Kessiby et al., 2008). The present study extends this dissociation to blind subjects, who showed the same task-dependent differences in errors.

These findings suggest that proprioceptive information can be used efficiently to estimate and control hand orientation during reaching movements. Similarly, growing evidence suggests that proprioception can be as, or even more, important than vision for 
estimation of hand distance in space (van Beers et al., 2002; Snijders et al., 2007). Moreover, in some conditions proprioceptive inputs represent the dominant sensory information used for mental motor imagery and on-line representation of the body in space (Shenton et al., 2004).

The reduction in hand orientation errors at the end of the reaching movements in letter-posting tasks in blind subjects also provides further evidence for the role of proprioceptive input in the adjustment of hand orientation by on-line correction mechanisms during reaching movements to stationary targets (Gosselin-Kessiby et al., 2008). This finding is all the more striking because control of hand orientation during reaching could be prone to execution errors due to inaccuracies in outgoing motor commands and to passive mechanical perturbations of the hand away from its desired orientation. Our findings are consistent with other studies that suggested a role for proprioception in the on-line correction of hand direction and distance in response to visual perturbations of target or hand position (Sarlegna et al., 2003, 2004; Bagesteiro et al., 2006).

The correction mechanism appears to be automatic. In letterposting task 2, hand orientation errors decreased after the reach even though the subjects had presumably perceived that their hand was already at the desired orientation before beginning to reach and had been instructed to keep their hand in that initial orientation during the reach.

Because the task involved active reach and rotation, an efferent copy of the motor command could have contributed to the difference in performance compared with the orientation-matching task. However, the active orientation-matching task also involved motor commands to produce the active hand rotations. Nevertheless, both the blind and normally sighted subjects showed error patterns in the active orientation-matching task that were more similar to those in the passive orientation-matching task than to letter-posting task 1 . The origin of the difference in results may be that the letter-posting task involves a transitive action directed at a target object (the target slot), whereas the active wrist rotation in the orientation-matching task was an intransitive action performed to report a perceptual estimation rather than to act on an object (Gosselin-Kessiby et al., 2008).

Alternatively, directing attention related to both the reach and orientation components to the same spatial location in letterposting task 1 may have enhanced performance relative to the hand rotations without reach in the orientation-matching tasks. However, the subjects may just as likely have attended equally to both tasks, which might predict that control of hand orientation would be poorer in letter-posting task 1 because of the need to attend to both hand orientation and spatial location. Furthermore, attention is divided in all tasks because of the need to also attend to the orientation of the reference handle in the left hand. Ultimately, we have no way to know how subjects allotted attention to different aspects of each task.

Explanations that invoke transitive actions or attention imply that the causal mechanisms are central in origin and ignore biomechanical aspects of the tasks. Another possibility is that during the reach in letter-posting task 1 , the motor system makes efficient use of all the redundant degrees of rotational freedom of all arm joints that contribute to hand orientation, which cannot occur when the arm is held outstretched in the orientation-matching tasks. None of these explanations are mutually exclusive.

\section{The role of visual experience}

Performance of congenitally blind and postnatally blind subjects was statistically identical in all tasks and similar to normally sighted subjects, suggesting that visual experience did not influence proprioceptive perception or the control of reach-andorient movements. Our findings are consistent with other reports that congenitally blind subjects performed similarly to those with acquired blindness and that early visual experience is not necessary to perform many tasks (Vanlierde and Wanet-Defalque, 2004; Gaunet and Rossetti, 2006; Goldreich and Kanics, 2006; Heller et al., 2001, 2002a,b). Furthermore, developmental studies showed no differences in pointing between congenitally blind and blindfolded normally sighted children and suggested that early visual experience and age do not predict pointing performance in children (Gaunet et al., 2007). Finally, our findings agree with a recent report that visual experience is not necessary for the activation of PPC during kinesthetically guided hand movements in congenitally blind subjects (Fiehler et al., 2009).

These various findings indicate that the dorsal "action" system processes multimodal sensory inputs, including both visual and proprioceptive, to guide actions, and that the development of this action control system is not dependent on visual experience.

\section{Interaction between target orientation and hand transport velocity}

A functional coupling between hand orientation and hand transport was observed in blind and blindfolded normally sighted subjects. Peak velocities of both hand transport and rotation increased for progressively larger target orientations in letterposting task 1 (Fig. 3). Such coupling is in agreement with a temporal coupling between hand transport velocity and hand grip aperture observed during reach to grasp in blind subjects (Castiello et al., 1993). The similarity of the coordination of hand transport and hand rotation velocities in blind subjects and blindfolded normally sighted subjects suggests that the global coordination of different components of reach-and-orient and reach-to-grasp actions does not depend on visual experience. Nevertheless, this coordination could be achieved by different mechanisms in blind and sighted subjects.

\section{References}

Alary F, Goldstein R, Duquette M, Chapman CE, Voss P, Lepore F (2008) Tactile acuity in the blind: a psychophysical study using a twodimensional angle discrimination task. Exp Brain Res 187:587-594.

Bagesteiro LB, Sarlegna FR, Sainburg RL (2006) Differential influence of vision and proprioception on control of movement distance. Exp Brain Res 171:358-370.

Binkofski F, Buccino G, Posse S, Seitz RJ, Rizzolatti G, Freund H (1999) A fronto-parietal circuit for object manipulation in man: evidence from an fMRI-study. Eur J Neurosci 11:3276-3286.

Buneo CA, Andersen RA (2006) The posterior parietal cortex: sensorimotor interface for the planning and online control of visually guided movements. Neuropsychologia 44:2594-2606.

Castiello U, Bennett KM, Mucignat C (1993) The reach to grasp movement of blind subjects. Exp Brain Res 96:152-162.

Coluccia E, Mammarella IC, De Beni R, Ittyerah M, Cornoldi C (2007) Remembering object position in the absence of vision: egocentric, allocentric, and egocentric decentred frames of reference. Perception 36:850-864.

Culham JC, Danckert SL, DeSouza JF, Gati JS, Menon RS, Goodale MA (2003) Visually guided grasping produces fMRI activation in dorsal but not ventral stream brain areas. Exp Brain Res 153:180-189.

Darling WG, Miller GF (1993) Transformations between visual and kinesthetic coordinate systems in reaches to remembered object locations and orientations. Exp Brain Res 93:534-547.

Darling WG, Seitz RJ, Peltier S, Tellmann L, Butler AJ (2007) Visual cortex activation in kinesthetic guidance of reaching. Exp Brain Res 179:607-619.

Day BL, Lyon IN (2000) Voluntary modification of automatic arm movements evoked by motion of a visual target. Exp Brain Res 130:159-168. 
Desmurget M, Grafton S (2000) Forward modeling allows feedback control for fast reaching movements. Trends Cogn Sci 4:423-431.

Desmurget M, Epstein CM, Turner RS, Prablanc C, Alexander GE, Grafton ST (1999) Role of the posterior parietal cortex in updating reaching movements to a visual target. Nat Neurosci 2:563-567.

Dijkerman HC, de Haan EH (2007) Somatosensory processes subserving perception and action. Behav Brain Sci 30:189-201; discussion 201-239.

Dyde RT, Milner AD (2002) Two illusions of perceived orientation: one fools all of the people some of the time; the other fools all of the people all of the time. Exp Brain Res 144:518-527.

Ernst MO, Banks MS (2002) Humans integrate visual and haptic information in a statistically optimal fashion. Nature 415:429-433.

Fan J, He J, Tillery SI (2006) Control of hand orientation and arm movement during reach and grasp. Exp Brain Res 171:283-296.

Fiehler K, Burke M, Engel A, Bien S, Rösler F (2008) Kinesthetic working memory and action control within the dorsal stream. Cereb Cortex 18:243-253.

Fiehler K, Burke M, Bien S, Röder B, Rösler F (2009) The human dorsal action control system develops in the absence of vision. Cereb Cortex 19:1-12.

Frey SH, Vinton D, Norlund R, Grafton ST (2005) Cortical topography of human anterior intraparietal cortex active during visually guided grasping. Brain Res Cogn Brain Res 23:397-405.

Gaunet F, Rossetti Y (2006) Effects of visual deprivation on space representation: immediate and delayed pointing toward memorised proprioceptive targets. Perception 35:107-124.

Gaunet F, Ittyerah M, Rossetti Y (2007) Pointing at targets by children with congenital and transient blindness. Exp Brain Res 178:167-179.

Glover S (2004) Separate visual representations in the planning and control of action. Behav Brain Sci 27:3-24; discussion 24-78.

Glover S, Dixon P (2001a) Dynamic illusion effects in a reaching task: evidence for separate visual representations in the planning and control of reaching. J Exp Psychol Hum Percept Perform 27:560-572.

Glover S, Dixon P (2001b) The role of vision in the on-line correction of illusion effects on action. Can J Exp Psychol 55:96-103.

Glover S, Dixon P (2001c) Motor adaptation to an optical illusion. Exp Brain Res 137:254-258.

Goldreich D, Kanics IM (2003) Tactile acuity is enhanced in blindness. J Neurosci 23:3439-3445.

Goldreich D, Kanics IM (2006) Performance of blind and sighted humans on a tactile grating detection task. Percept Psychophys 68:1363-1371.

Goodale MA, Milner AD (1992) Separate visual pathways for perception and action. Trends Neurosci 15:20-25.

Goodale MA, Pelisson D, Prablanc C (1986) Large adjustments in visually guided reaching do not depend on vision of the hand or perception of target displacement. Nature 320:748-750.

Gosselin-Kessiby N, Messier J, Kalaska JF (2008) Evidence for automatic on-line adjustments of hand orientation during natural reaching movements to stationary targets. J Neurophysiol 99:1653-1671.

Grant AC, Thiagarajah MC, Sathian K (2000) Tactile perception in blind Braille readers: a psychophysical study of acuity and hyperacuity using gratings and dot patterns. Percept Psychophys 62:301-312.

Gréa H, Pisella L, Rossetti Y, Desmurget M, Tilikete C, Grafton S, Prablanc C, Vighetto A (2002) A lesion of the posterior parietal cortex disrupts online adjustments during aiming movements. Neuropsychologia 40:2471-2480.

Heller MA (1989) Tactile memory in sighted and blind observers: the influence of orientation and rate of presentation. Perception 18:121-133.

Heller MA, Kennedy JM (1990) Perspective taking, pictures, and the blind. Percept Psychophys 48:459-466.

Heller MA, Brackett DD, Scroggs E, Allen AC, Green S (2001) Haptic perception of the horizontal by blind and low-vision individuals. Perception 30:601-610.

Heller MA, Brackett DD, Scroggs E, Steffen H, Heatherly K, Salik S (2002a) Tangible pictures: viewpoint effects and linear perspective in visually impaired people. Perception 31:747-769.

Heller MA, Brackett DD, Wilson K, Yoneyama K, Boyer A, Steffen H (2002b) The haptic Muller-Lyer illusion in sighted and blind people. Perception 31:1263-1274.

Hocherman S (1993) Proprioceptive guidance and motor planning of reaching movements to unseen targets. Exp Brain Res 95: 349-358.

Iacoboni M (2006) Visuo-motor integration and control in the human posterior parietal cortex: evidence from TMS and fMRI. Neuropsychologia 44:2691-2699.

Imbiriba LA, Rodrigues EC, Magalhães J, Vargas CD (2006) Motor imagery in blind subjects: the influence of the previous visual experience. Neurosci Lett 400:181-185.

Ittyerah M, Gaunet F, Rossetti Y (2007) Pointing with the left and right hands in congenitally blind children. Brain Cogn 64:170-183.

Jakobson LS, Goodale MA (1991) Factors affecting higher-order movement planning: a kinematic analysis of human prehension. Exp Brain Res 86:199-208.

Jeannerod M (1984) The timing of natural prehension movements. J Mot Behav 16:235-254.

Milner AD, Goodale MA (2008) Two visual systems re-viewed. Neuropsychologia 46:774-785.

Murata A, Gallese V, Luppino G, Kaseda M, Sakata H (2000) Selectivity for the shape, size, and orientation of objects for grasping in neurons of monkey parietal area AIP. J Neurophysiol 83:2580-2601.

Oldfield RC (1971) The assessment and analysis of handedness: the Edinburgh inventory. Neuropsychologia 9:97-113.

Pélisson D, Prablanc C, Goodale MA, Jeannerod M (1986) Visual control of reaching movements without vision of the limb. II. Evidence of fast unconscious processes correcting the trajectory of the hand to the final position of a double-step stimulus. Exp Brain Res 62:303-311.

Pisella L, Gréa H, Tilikete C, Vighetto A, Desmurget M, Rode G, Boisson D, Rossetti Y (2000) An 'automatic pilot' for the hand in human posterior parietal cortex: toward reinterpreting optic ataxia. Nat Neurosci 3:729-736.

Prablanc C, Martin O (1992) Automatic control during hand reaching at undetected two-dimensional target displacements. J Neurophysiol 67:455-469.

Rice NJ, Tunik E, Grafton ST (2006) The anterior intraparietal sulcus mediates grasp execution, independent of requirement to update: new insights from transcranial magnetic stimulation. J Neurosci 26:8176-8182.

Rossetti Y, Desmurget M, Prablanc C (1995) Vectorial coding of movement: vision, proprioception, or both? J Neurophysiol 74:457-463.

Rossetti Y, Gaunet F, Thinus-Blanc C (1996) Early visual experience affects memorization and spatial representation of proprioceptive targets. Neuroreport 7:1219-1223.

Sakata H, Taira M, Kusunoki M, Murata A, Tanaka Y (1997) The Trends Neurosci Lecture. The parietal association cortex in depth perception and visual control of hand action. Trends Neurosci 20:350-357.

Sarlegna F, Blouin J, Bresciani JP, Bourdin C, Vercher JL, Gauthier GM (2003) Target and hand position information in the online control of goal-directed arm movements. Exp Brain Res 151:524-535.

Sarlegna F, Blouin J, Vercher JL, Bresciani JP, Bourdin C, Gauthier GM (2004) Online control of the direction of rapid reaching movements. Exp Brain Res 157:468-471.

Sarlegna FR, Sainburg RL (2007) The effect of target modality on visual and proprioceptive contributions to the control of movement distance. Exp Brain Res 176:267-280.

Saunders JA, Knill DC (2003) Humans use continuous visual feedback from the hand to control fast reaching movements. Exp Brain Res 152:341-352.

Saunders JA, Knill DC (2004) Visual feedback control of hand movements. J Neurosci 24:3223-3234.

Saunders JA, Knill DC (2005) Humans use continuous visual feedback from the hand to control both the direction and distance of pointing movements. Exp Brain Res 162:458-473.

Sergio LE, Scott SH (1998) Hand and joint paths during reaching movements with and without vision. Exp Brain Res 122:157-164.

Shenton JT, Schwoebel J, Coslett HB (2004) Mental motor imagery and the body schema: evidence for proprioceptive dominance. Neurosci Lett 370:19-24.

Snijders HJ, Holmes NP, Spence C (2007) Direction-dependent integration of vision and proprioception in reaching under the influence of the mirror illusion. Neuropsychologia 45:496-505. 
Sober SJ, Sabes PN (2003) Multisensory integration during motor planning. J Neurosci 23:6982-6992.

Sober SJ, Sabes PN (2005) Flexible strategies for sensory integration during motor planning. Nat Neurosci 8:490-497.

Sunanto J, Nakata H (1998) Indirect tactual discrimination of heights by blind and blindfolded sighted subjects. Percept Mot Skills 86:383-386.

Tunik E, Frey SH, Grafton ST (2005) Virtual lesions of the anterior intraparietal area disrupt goal-dependent on-line adjustments of grasp. Nat Neurosci 8:505-511.

Tunik E, Ortigue S, Adamovich SV, Grafton ST (2008) Differential recruitment of anterior intraparietal sulcus and superior parietal lobule during visually guided grasping revealed by electrical neuroimaging. J Neurosci $28: 13615-13620$ van Beers RJ, Sittig AC, Gon JJ (1999) Integration of proprioceptive and visual position-information: an experimentally supported model. J Neurophysiol 81:1355-1364.

van Beers RJ, Wolpert DM, Haggard P (2002) When feeling is more important than seeing in sensorimotor adaptation. Curr Biol 12:834-837.

Van Boven RW, Hamilton RH, Kauffman T, Keenan JP, Pascual-Leone A (2000) Tactile spatial resolution in blind Braille readers. Neurology 54:2230-2236.

Vanlierde A, Wanet-Defalque MC (2004) Abilities and strategies of blind and sighted subjects in visuo-spatial imagery. Acta Psychol (Amst) 116:205-222.

Wing AM, Turton A, Fraser C (1986) Grasp size and accuracy of approach in reaching. J Mot Behav 18:245-260 . 